\title{
Traditional and Novel Caries Detection Methods
}

\author{
Michele Baffi Diniz ${ }^{1}$, Jonas de Almeida Rodrigues ${ }^{2}$ and Adrian Lussi ${ }^{3}$ \\ ${ }^{1}$ Cruzeiro do Sul University, \\ ${ }^{2}$ Federal University of Rio Grande do Sul, \\ ${ }^{3}$ University of Bern, \\ 1,2 Brazil \\ ${ }^{3}$ Switzerland
}

\section{Introduction}

Dental caries is a bacteria-associated progressive process of the hard tissues of the coronal and root surfaces of teeth. The net demineralization may begin soon after tooth eruption in caries susceptible children without being recognized by dental professionals. This process may progress further resulting in a caries lesion that is the sign and/or the symptom of the carious process. Caries is in other words a continuum which may by assessed falsely when only a certain time point is considered. Figure 1 shows different stages of the carious process.

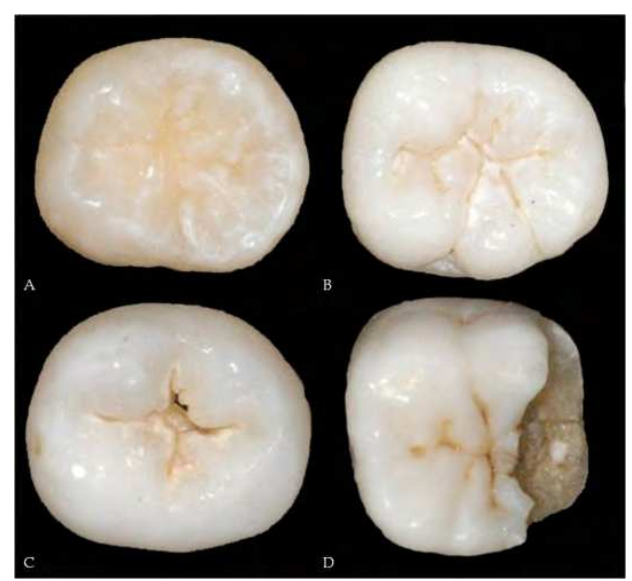

Fig. 1. (A) Sound occlusal surface. (B-D) Caries process in different stages.

Caries diagnosis implies more than just detecting lesions. Consequently, caries diagnosis as an intellectual process - is the determination of the presence and extent of a caries lesion. Furthermore the judgement of its activity is an integral part of diagnosis.

Since diagnosis is a mental resting place on the way to treatment decision, it is intimately linked with the treatment plan to be followed. Thus diagnosis must include an assessment 
of activity because active lesions require active management (non-operative and operative treatment) whereas arrested lesions do not. The problem, however, is the assessment of the activity. The detection process may miss lesions (false negatives) or may overlook lesions that are present (false positives). The assessment of activity may be similarly wrong. For treatment decisions made in the clinic, the diagnosis should also express the individual patient's caries activity, which may be defined as the sum of new caries lesions and the enlargement of existing lesions during a given time (Wyne, 1993). It is a compound diagnosis comprising the immediate past caries experience, lesion progression and the clinical appearance of the lesions. The most important parameters for estimation of caries activity are the clinical appearance of a lesion and patient factors such as salivary flow, sugar intake and oral hygiene (Lagerlöf \& Oliveby, 1996). Thus, caries activity can be evaluated by the assessment of factors associated with the pathogenesis of the disease and on the basis of data obtained from clinical examination. There are some clinical signs to get some idea of lesion's activity. An active initial lesion is dull and has a rough surface, it shows bleeding on probing in a patient with otherwise healthy periodontal conditions, it may be covered with plaque and on vestibular surfaces it is more adjacent to the gingival margin. An inactive lesion is shiny and has a smooth surface, and it is less adjacent to the gingival margin (Figure 2).

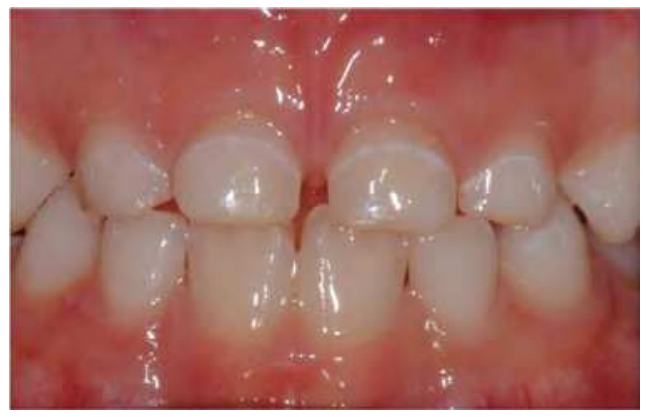

Fig. 2. Inactive carious lesion on the buccal surface. Note the shiny appearance and the position at some distance from the gingival margin.

Clinical-visual diagnosis may be amenable to longitudinal monitoring even though the assessment is qualitative. It would be easier to have a device that would not only detect demineralization but quantify it as well. Then monitoring progression or arrestment would be simple; use the device again and see in what direction the numbers change. The concept is hugely appealing so no wonder researchers have made such efforts to develop, test and perfect such devices. All these methods for caries detection are based on the interpretation of one or more physical signals. These are causally related to one or more features of a caries lesion. First, the signals must be received using a receptor device and classified. The classification of a signal is part of the diagnostic decision-making process. However, none of the methods is capable of processing all these signals to a status that could be called diagnosis. "The art of identifying a disease from its signs and symptoms" is a process that cannot be replaced by a machine or a device.

Caries measurement should be seen in the context of the objectives of modern clinical caries management and the continuum of disease states, ranging from sub-surface carious changes 
through to more advanced lesions (Figure 3). Measurement concepts can be applied to at least three levels: the tooth surface, the individual, or the group/population. According to Pitts (2004) modern clinical caries management can be seen as comprised by seven discrete but linked steps: (1) Caries detection represents a yes/no decision as to whether caries is present; (2) lesion measurement assesses defined stages of the caries process, taking into account the histopathological morphology and appearance of different sizes and types of lesion and the diagnostic threshold(s) being used; (3) lesion monitoring by repeated measures at a series of examinations is used when lesions are less advanced than the stage judged to require operative intervention of preventive care aiming either to arrest or to reverse the lesion to be assessed; (4) caries activity measures would be very valuable, but are relatively poorly developed and tested at present; (5) diagnosis, prognosis, and clinical decision-making are the important human processes in which all the information obtained from steps 1 to 4 is synthesized; (6) interventions/treatments, both preventive and operative, are now routinely used for caries management; and (7) outcome of caries control/management assesses caries management by examining evidence on the long-term outcomes.

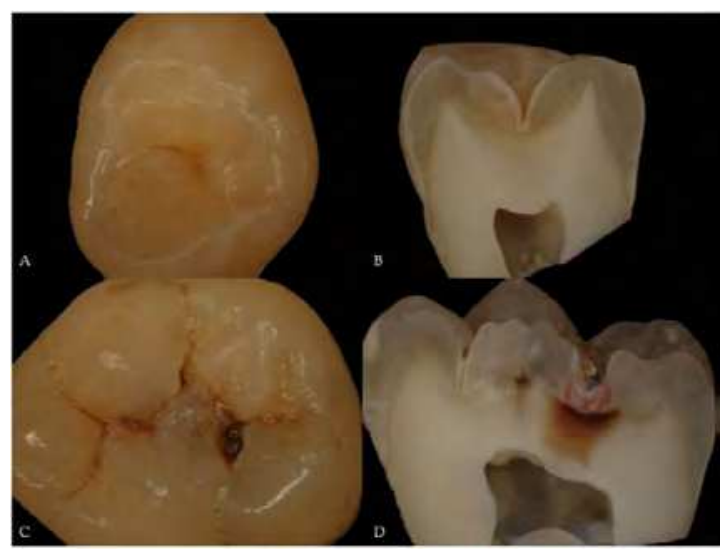

Fig. 3. (A) Initial carious lesion on occlusal surface. (B) Histological section through the lesion. The acid resistant and fluoride rich superficial layer is clearly visible. (C) Dentinal occlusal caries with cavitation and shadow. (D) Histological section through the lesion.

Early diagnosis of the caries lesion is important because the carious process can be modified by preventive treatment so that the lesion does not progress. If the caries disease can be diagnosed at an initial stage (e.g. white spot lesion) the balance can be tipped in favour of arrestment of the process by modifying diet, improving plaque control, and appropriate use of fluoride. Using non-invasive quantitative diagnostic methods it should be possible to detect lesions at an initial stage and subsequently monitor lesion changes over time during which preventive measures could be introduced.

\section{Evaluation of the performance of caries detection methods}

The performance of caries detection methods should be assessed considering two important parameters: reproducibility and validity. A reproducible method is the one that presents similar results and shows an agreement between two exams performed in different 
moments or by different examiners using the same sample. Reproducibility can be assessed by Cohen's Kappa test or Intraclass Correlation Coefficient (ICC).

Validity is the ability of a method of assessing what it is suppose to assess. It is calculated by the proportion of correct results taking into account the gold standard, which is the true and definitive diagnosis reference. Using these results, the validity of a method can be obtained by calculating values of specificity and sensitivity. Specificity is the proportion of cases classified by a method as negative (disease absent) considering the total of cases that did not developed the disease. Sensitivity, however, is the proportion of cases classified as positive (disease present) considering the total of cases that really developed the disease. The total percentage of correctly assessed cases considering the presence and the absence of disease is represented by the accuracy. Table 1 summarizes how sensitivity $(\mathrm{Sn})$ and specificity $(\mathrm{Sp})$ values can be calculated:

\begin{tabular}{|c|c|c|c|}
\hline & Disease present (+) & Disease absent (-) & \\
\hline Positive Test (+) & A & $B$ & $\begin{array}{l}\text { Total positive } \\
\text { tests }(\mathrm{A}+\mathrm{B})\end{array}$ \\
\hline \multirow[t]{2}{*}{ Negative Test (-) } & C & $\mathrm{D}$ & $\begin{array}{l}\text { Total negative } \\
\text { tests }(C+D)\end{array}$ \\
\hline & Sn $\%: A /(A+C)$ & Sp\%: D/(B + D) & $\begin{array}{l}\text { Total number (A } \\
+\mathrm{B}+\mathrm{C}+\mathrm{D})\end{array}$ \\
\hline
\end{tabular}

Table 1. The generic $2 \times 2$ table used to calculate sensitivity (Sn) and specificity (Sp) values.

Concerning methods' validity and calculation of sensitivity and specificity values it is necessary to establish limits to define what "disease" and "healthy" mean considering the gold standard. These limits can also be called "cut-off points", which are combined according to the criteria used for the gold standard classification. For example, caries lesions can be classified in: (0) caries free, (1) caries extending up to halfway through the enamel, (2) caries extending into the inner half of enamel, (3) caries in dentin and (4) deep dentin caries. Therefore, cut-off points can be defined as follow:

$\mathrm{D}_{1}$ : all caries lesions are considered disease (1, 2, 3 and 4);

$\mathrm{D}_{2}$ : only caries lesions from the inner half of enamel are considered disease (2, 3 and 4$)$;

$\mathrm{D}_{3}, \mathrm{D}_{4}$ : only dentin caries lesions are considered disease ( 3 and 4 ).

\section{Clinical and histological aspects of caries lesions on occlusal, approximal and smooth surfaces}

The occlusal surface is characterized by the pit and fissure systems, a favorable biofilm stagnation area where the bacterial accumulations receive the best protection against functional/mechanical wear (mastication, attrition, abrasion from brushing, flossing or toothpicks). Those aspects contribute to the high prevalence of caries on occlusal surfaces both in the primary and permanent dentition (Kidd \& Fejerskov, 2004).

The complex anatomy of the occlusal surfaces requires professional special attention and deep understanding of how lesions develop on this surface. It is known that the deepest part of the fissure usually harbors non-vital bacteria or calculus (Ekstrand \& Bjørndal, 1997). An enamel caries lesion begins along the pits and fissures through acids diffusion from bacterial metabolism in the biofilm. This diffusion occurs through the side walls of the pits and 
fissures, guided by prisms direction and striae of Retzius. Histologically, the lesion forms in three dimensions and assumes the shape of a cone, with its base toward the enamel-dentin junction. Acids lead to the demineralization underneath the enamel surface and there is an enlargement in intercrystalline spaces, increasing its permeability. Over time, the surface porosity has increased and leads to a considerable increase of the lesion body (a subsurface lesion starts to form). Occlusal enamel breakdown is the result of further demineralization, thus leading to cavity formation (Nyvad et al., 2008).

The lesions on smooth surfaces result from an accumulation of biofilm along the gingival margins. Characteristically, those lesions follow the form of the gingival contour and can progress to form a cavity in enamel, and subsequently, that can extend through the dentin (Nyvad et al., 1999). In section, the smooth-surface lesion is conical as a result of systematic variations in dissolution along the enamel prisms. The conically shaped lesion represents a range of increasing stages of lesion progression, beginning with dissolution at the ultrastructural level at the edge of the lesion (Bjørndal \& Thylstrup, 1995).

On the approximal surfaces, the biofilm accumulation occurs in the region below the contact point between the contact face and the gingival margin. The lesion may extend to the buccal and lingual directions, following the gengival contour (Nyvad et al., 1999). Histologically, the initial lesion in the approximal surface has a triangular shape with its base toward the outer surface and the apex facing the enamel-dentin junction. As mentioned earlier, this is because the acid diffusion from the bacterial metabolism is determined by the distribution of the biofilm and follows the direction of the enamel prisms (Nyvad et al., 2008).

Caries lesion on approximal surfaces in primary teeth presents a rapid rate of progression due to the morphologic characteristics of these teeth, making its detection difficult. Primary teeth have thinner enamel and dentin, lower mineralization rate, large dentinal tubules and larger contact proximal areas, which allow greater biofilm accumulation, and consequently, leading to initiation and progression of dental caries (Mortimer, 1970; Pitts \& Rimmer, 1992).

\section{Caries detection methods}

The detection of carious lesions has been primarily a visual process, based principally on clinical-tactile inspection and radiographic examination. Caries detection methods should be capable of detecting lesions at an early stage, when progression can be arrested or reserved, avoiding premature tooth treatment by restorations. However, none of the conventional methods fulfill this requirement and are highly subjective. The development of some alternative non-invasive detection methods, such as laser fluorescence devices (DIAGNOdent and DIAGNOdent pen), quantitative light-induced fluorescence (QLF), fluorescence camera (VistaProof), LED technology (Midwest Caries I.D.), fiber-optic transillumination (FOTI), digital imaging fiber-optic transillumination (DIFOTI) and electrical caries monitor (ECM), can offer objectives assessments, where traditional methods could be supplemented by quantitative measurements.

\subsection{Visual-tactile examination}

Visual changes of the dental structure resulting from the demineralization process can be visually observed during caries development, such as an increase in opacity and roughness of the enamel. 
Visual examination has been widely used in dental clinics for detecting carious lesions on all surfaces. This method is based on the use of a dental mirror, a sharp probe and a 3-in-1 syringe and requires good lighting and a clean/dry tooth surface (Hamilton, 2005). The examination is based primarily on subjective interpretation of surface characteristics, such as integrity, texture, translucency/opacity, location and color (Ekstrand et al., 1997; Nyvad et al., 1999). However, tactile examination of dental caries has been criticized because of the possibility of transferring cariogenic microorganisms from one site to another, leading to the fear of further spread of the disease in the same oral cavity. Moreover, use of an explorer can cause irreversible damages to the iatrogenic and demineralized tooth structure (Ekstrand et al., 1987; Stookey, 2005; Loesche et al., 1979).

Tooth separation can be used as a method for examination of a suspicious area on the approximal surface. With this technique an orthodontic elastic separator can be applied for 2-3 days around the contact areas of approximal surfaces, facilitating the clinical and probing assessments. However, this method might create some discomfort and requires an extra visit (Araújo et al., 1996). Studies have shown that tooth separation have detected more non-cavitated enamel lesions than visual-tactile examination without separation or bitewing examination (Hintze et al., 1998; Pitts \& Rimmer, 1992).

Nyvad's system (Nyvad et al., 1999) is a reliable method for activity assessment of noncavitated and cavitated caries lesions. According to this system, the examination is based only on clinical features of the surface (color, opacity and presence of discontinuities or cavitations), classifying the lesion as inactive or active. The original system used biofilm accumulation as an indicator for caries activity and used a sharp dental explorer to assess surface roughness. However, the Nyvad system was modified; adopting the use of a ballended probe should be gently drawn across the surface in order to assess its texture (rough or smooth) and also to remove the biofilm (Braga et al., 2009). If the lesion is active and cavitated, operative treatment is recommended. If active and non-cavitated, non-operative, preventive treatment is recommended (Nyvad, 2004). For detecting carious lesions, the examination should be mainly based on careful visual assessment on a clean/dry surface, without probing. An important aspect of caries detection is that the surface must be dry because saliva can mask differences in the reflection of light between carious and healthy tooth structure, hindering the observation of changes in color and brightness on the enamel surface. The criteria scores identify sound and active/inactive primary or secondary caries lesions. The Nyvad system has been shown to have good reproducibility and also construct and predictive validity for assessment of caries activity (Nyvad et al., 1999, 2003).

Visual examination has been show to have a high specificity but low sensitivity and reproducibility (Bader et al., 2001). Therefore, different criteria have been proposed to provide defined descriptors of different severity stages of caries lesions (Ekstrand et al., 1997; Ismail et al., 2007; Nyvad et al., 1999).

After the analysis of a systematic review presented in a conference in the USA and in the International Consensus Workshop on Caries Clinical Trials held in Scotland, it was concluded that the reliability and reproducibility of currently available caries detection / diagnostic systems, including visual and visual-tactile criteria, were not strong (Bader et al., 2001; Pitts \& Stamm, 2002). Based on these findings, a new visual criterion has been introduced for caries detection. 
The International Caries Detection \& Assessment System (ICDAS) was developed and introduced by an international group of researchers (cariologists and epidemiologists) to provide clinicians, epidemiologists, and researchers with an evidence-based system for caries detection (Pitts, 2004). This method was devised based on the principle that the visual examination should be carried out on clean, plaque-free teeth, with carefully drying of the lesion / surface to identify early lesions. According to this system, the replacement of the traditional explorers and sharp probes with a ball-ended periodontal probe would avoid traumatic and iatrogenic defects on incipient lesions (Ekstrand et al., 2007; Ismail et al., 2007; Jablonski-Momeni et al., 2007).

ICDAS is a two-digit identification system. Initially, the status of the surface is described as unrestored, sealed, restored or crowned. After that, a second code is attributed to identify six stages of caries extension, varying from initial changes visible in enamel to frank cavitation in dentine (Ekstrand et al., 2007; Ismail et al., 2007; Zandoná \& Zero, 2006). Some studies have shown good reproducibility and accuracy of ICDAS for occlusal caries detection at different stages of the disease in permanent (Diniz et al., 2009, 2011; Ekstrand et al., 2007; Jablonski-Momeni et al., 2007; Rodrigues et al., 2008) and in primary teeth (Braga et al., 2009; Neuhaus et al., 2010; Shoiab et al., 2009). The literature has suggested that the ICDAS criteria have potential to aid treatment planning (Diniz et al., 2011; Longbottom et al., 2009; Pitts \& Richards, 2009).

ICDAS was developed with the mission to devise a set of international visual criteria for caries detection that would also allow assessment of caries activity (Ekstrand et al., 2007). The Lesion Activity Assessment (LAA) criteria have been developed for use in association with the ICDAS scoring system based on using weighted numerical values for lesion appearance (ICDAS score of the lesion), lesion location in relation to a cariogenic plaque stagnation area and surface integrity by tactile sensation when a ball-ended probe is gently drawn across the surface (Ekstrand et al., 2007; Varma et al., 2008). This evaluation involves the characterization of the caries lesion activity during a single clinical examination, in real time, in order to determine whether intervention is necessary (Ekstrand et al., 2009). The association of the LAA and the ICDAS codes involves lesion detection and coding, thereby estimating its depth or severity, and assessing its activity (Braga et al., 2009). An in vitro study found that there is no major difference between the Nyvad system and the ICDASLAA in assessing caries activity in primary teeth (Braga et al., 2009). However, in a clinical study ICDAS-LAA seems to overestimate the caries activity assessment of cavitated occlusal lesions in primary teeth compared to the Nyvad system (Braga et al., 2010).

Despite being the most widely used method in clinical practice, many studies have shown that visual-tactile examination should be associated with other caries detection methods, such as bitewing radiographs, especially for early caries lesions detection in approximal surfaces and for lesion depth evaluation on occlusal surfaces (Lussi, 1993; Lussi et al., 2006; Sanden et al., 2003; Wenzel, 2004).

\subsection{X-ray based methods}

The discovery of X-rays by Wilhelm Conrad Roentgen in 1895 provided a major advance in diagnostic imaging. In dental field, the North American dentist Edmund Kells began experimenting with radiography in 1986, becoming the pioneer of dental radiology. 
Since then, the use of X-rays and radiographic films promoted a significant jump in the direction of dental therapy, since it provided substantial contribution in obtaining the diagnosis. In addition, radiographic techniques have been modified to acquire optimum Xray quality and to increase diagnostic possibilities, as for detecting caries lesions.

\subsubsection{Conventional radiography}

Radiography is the most common caries lesion detection aid. It is fundamentally based on the fact that as the caries progress proceeds, the mineral content of enamel and dentin decreases, resulting in a decrease in the attenuation of the X-ray beam as it passes through the teeth. This feature is recorded on the image receptor as an increase in radiographic density. Clinically, the detection of carious lesions is based on a combination of visual-tactile and radiographic examination.

Bitewing radiography has been used for the detection and evaluation of caries lesions depth, which are invisible or poorly visible for inspection. Thus, radiography is mainly used for the detection of carious lesions in approximal surfaces, but is also recommended as a supplement for occlusal caries detection. However, experiments have shown that, once an occlusal carious lesion is clearly visible on radiographs, histological examination shows that demineralization has extended to or beyond the middle third of the dentin (Ricketts et al., 1995). Therefore, radiographic examination may underestimate the extent of caries lesions (Dove, 2001).

Bitewing radiography presents a tendency to make false-positive scores, and this could be due to the Mach-band effect, a perceptual phenomenon in which there is an enhancement of the contrast between a dark and a relatively lighter area, resulting in a dark band sharply demarcated (Berry, 1983). This effect causes an inclination to see radiolucency in the dentinenamel junction where no dentin lesion is actually present (Espelid et al., 1994). Another effect, called cervical burnout, can be erroneously interpreted as cervical caries, once a collar or wedge-shaped radiolucency occurs between the bone height and the cemento-enamel junction (CEJ). This effect is an optical illusion phenomenon, due to the tissue density and the variable penetration of X-ray at the cervical region of the tooth and the regions above and below it, which produces a dark shadow on the radiograph due to lower absorption of photons in the neck of the tooth (Berry, 1983). For these reasons, radiographs should be interpreted with caution and requires constant retraining, updating, experience and information of the human observer (Diniz et al., 2010).

Several criteria are used to classify the extent of carious lesions on radiographs, such as (0) absence of radiolucency, (1) radiolucency in the outer half of the enamel, (2) radiolucency on the inner half of the enamel, which can extend up to the dentin-enamel junction (DEJ), (3) radiolucency in the outer half of the dentin and (4) radiolucency in the inner half of the dentin toward the pulp chamber (Mejàre \& Kidd, 2008).

Regarding the performance of bitewing radiography, studies have found that the X-rays show a high sensitivity (50-70\%) to detect caries lesions in dentin of both approximal and occlusal surfaces, compared to clinical visual detection. However, the validity of detecting enamel lesions is limited on the approximal surfaces and low for the occlusal surfaces (Wenzel, 1995, 2004). This difference can be explained by the fact that radiography is a 2dimensional image of a 3-dimensional anatomy of the tooth structure. So, the superimposed 
cuspal tissues obscure initial changes in occlusal surfaces (Espelid et al., 1994; Neuhaus et al., 2009). In a systematic review of the literature, the evidence suggests that radiographs have high specificity and low sensitivity for caries detection. In other words, this means that there are great chances to occur false-negative diagnosis in the presence of caries than falsepositive diagnosis in the absence of disease (Dove, 2001).

It is important to stress that many different factors can affect the ability of bitewing radiography to accurately detect lesions, such as technique, image processing, type of image receptor, exposure parameters, vertical and horizontal angulations of the X-ray beam, positioning of the film, display system, viewing conditions, possible distortions caused by the structures attached to the dental tissues and failures of interpretation, which can lead to an incorrect diagnosis (Dove, 2001).

Radiographic examination is useful in monitoring caries lesion development, in view of the fact that non-cavitated lesions can be reversed by non-invasive intervention, providing changes in mineral content of dental tissues. However, there are limits to the radiographic examination which should be considered, particularly since lesion behavior has changed, with cavitation occurring much later than previously (Pitts \& Rimmer, 1992), Thus, it is worth remembering that radiography is not able to differentiate between an active and an arrested caries lesion, and to distinguish a cavitated and a non-cavitated lesion. According to Ratledge et al. (2001), 50-90\% of dentin caries lesions radiographically observed on the approximal surface might present cavitation. There are cases where clinically "sound" and apparently intact occlusal surfaces, however, may develop lesions which penetrate into the dentin, sometimes named "hidden" caries (Ricketts et al., 1997), which can be observed only through radiographic examination (Figure 4).

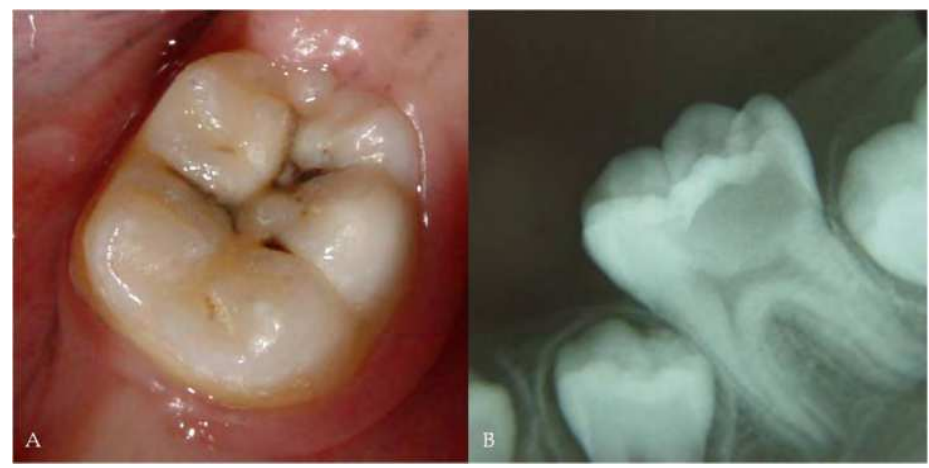

Fig. 4. Detection of occlusal caries. (A) Clinical aspect of a lesion in an intact surface. (B) Radiographic aspect of the lesion penetrating into the dentin - a typical "hidden caries".

Currently, there are some questions regarding specific indication of radiographs and intervals between subsequent radiographic examinations for caries detection. There is no evidence that routine radiographs will benefit a low caries risk population. In fact, this procedure can be harmful because it can induce a great risk of overdiagnosis, and consequently, an overtreatment. The frequency of taking radiographs depends on the individual caries risk, lesion activity and on the individual benefit to a patient (Neuhaus et al., 2009). 


\subsubsection{Digital radiography}

Digital radiography is a complementary method that has been available in dentistry for more than 25 years, but digital imaging has not replaced conventional film-based radiography completely. Studies have shown that the number of dental professionals using digital radiography in clinical practice range from $11 \%$ to $30 \%$. This fact can be attributed to the financial investment required to replace conventional radiography with digital imaging and also for the hesitancy to use a new technology, since it requires additional training on basic computer skills. On the other hand, a professional who is starting his/her career will not find huge differences in costs to acquire a conventional or a digital radiography system. Practitioners should remember that conventional radiography also involves costs for items, such as radiographic films, film mounts, processing solutions and time needed for cleaning the film processor (van der Stelt, 2008).

Studies have shown many advantages of digital radiography compared with conventional radiography. These include image acquisition process in real time, since the image is displayed immediately after exposure and no processing had to be performed. Other benefits include reductions in radiation dose (between $5 \%$ to $50 \%$ of the dose needed for conventional radiography) to obtain quality diagnostic images, time savings and digital manipulation of the image to enhance viewing, avoiding unnecessary or repeated radiographs. Digital images facilitate communication and case discussion among dental professionals, being a visual aid to be shown to the patient on the computer screen, increasing the confidence and credibility in the treatment-decision making process. However, the primary disadvantages of digital systems include the rigidity and thickness of the sensors, the high initial system cost and unknown sensor lifespan (Bin-Shuwaish et al., 2008; van der Stelt, 2008; Wenzel, 1998).

It is imperative to understand the digital radiography system to understand the principle of image manipulation. A digital image consists of a set of cells that are ordered in rows and columns, forming a table. Each cell is characterized by three numbers: the $x$-coordinate, the $\mathrm{y}$-coordinate and the gray value. The gray value is a number that corresponds with the $\mathrm{X}$ ray intensity at that location during the exposure of the digital sensor. Individual cells are called "picture elements", which had been shortened to "pixels". The numbers describing each pixel are stored in an image file in the computer. This feature is an essential difference between conventional and digital radiographs, once digital images can be modified after they have been produced. Thus, the user can apply mathematical operations (special algorithms or filters) to modify the pixel values, improving the image quality and modifying other characteristics, such as zoom, contrast, density and brightness of an image. The image numbers are converted into gray values and these are displayed on the computer screen as analog data. Then, the professional can assess and interpret the radiographic image produced (van der Stelt, 2008; Wenzel, 1998).

An example of useful image manipulation is the optimization of contrast and brightness of an image. This technique can be used to correct overexposure or underexposure of an image, although it is not an excuse to not pay attention to the correct exposure parameters. The manipulation can help to recover an image in which the exposure conditions were not optimal. This procedure may prevent the need for a radiograph remake, protecting the patient from an extra dose of radiation (van der Stelt, 2008). 
Digital image presents lower spatial resolution when compared to the image obtained by conventional radiography. The extension or palette for digital images is normally limited to 256 shades of gray, while more than a million shades of gray may appear for conventional X-ray film. Therefore, it can be speculated that the performance of digital radiography for caries detection would not be superior to that of conventional radiography. However, the performance of digital radiography for caries detection can be improved with image manipulation possibility, such as contrast modification. Thus, digital radiography systems seem to be as accurate as the conventional radiography system. According to a literature review, digital radiography showed high sensitivity for detecting occlusal caries lesions into dentin (60-80\%), with false-positives results of 5-10\% (Wenzel, 1998).

Undoubtedly, as technology evolves, it is supposed that the performance of digital radiography will be improved in a near future. The development of different sensors and software will support the reliability and viability of digital radiography applications by dental professionals, bringing this method to daily practice.

\subsubsection{Digital subtraction radiography}

Digital subtraction radiography (DSR) is a more advanced image analysis tools. This method allows professionals to distinguish small differences between subsequent radiographs that otherwise would have remained unobserved because of overprojection of anatomical structures or differences in density that are too small to be recognized by the human eye. The procedure is based on the principle that two digital radiographic images obtained under different time intervals, with the same projection geometry, are spatially and densitometrically aligned using specific software. When the two images are registered and intensities of corresponding pixels are subtracted of the gray scale values, a uniform difference image is produced, resulting in a new image representing the differences between the two, called the subtraction image. In this new image, if there is a change in the radiographic attenuation between the baseline and follow-up examination, all the anatomical structures that do no change between radiographs are shown as neutral gray background, while regions that had mineral loss or gain are shown as a darker or brighter area, respectively (van der Stelt, 2008; Wenzel, 2004).

For a successful DSR, reproducible exposure geometry, and also identical contrast and density of the serial radiographs, are essential prerequisites. Long experience shows that this technique is very sensitive to any physical noise occurring between the radiographs and even minor changes leads to large errors in the results (Hekmatian et al., 2005).

Digital subtraction radiography has been used in the assessment of the progression, arrest, or regression of caries lesions. Subtraction consists of subtracting the pixel values of the baseline image from the pixel values of the second image. If the two digital images are identical, this method will produce an image without details (the result is zero). However, if caries has regressed or progressed in the mean time, the result will be different from zero. When there is caries regression, the outcome will be a value above zero (increase in pixel values). In case of caries regression, the result is opposite and the outcome will be a value below zero (decrease in pixel values) (Hekmatian et al., 2005).

Few studies are found in the literature investigating the DRS for caries detection. The system works well for approximal and occlusal lesions in dentin, indicating that this method presents high potential for dental caries research (Neuhaus et al., 2009). 
Recently, a digital subtraction radiographic system was evaluated on occlusal surfaces (Ricketts et al., 2007). In this in vitro study, accuracy and reproducibility of DSR was compared to visual assessment of paired digital images in detecting changes in mineral content within occlusal cavities. Intra-examiner and inter-examiner reproducibility for detection of demineralization from the subtraction images was significantly better than viewing the paired images side by side. The subtraction radiography system used was found to be more accurate and reproducible than visual assessment of paired digital images, showing promising results for monitoring occlusal lesion progression in clinical studies.

It is important to clarify that DSR will not necessarily improve the detection of a caries lesion, but will only provide important information on any changes occurring over time, and is therefore, suitable for monitoring lesion behavior. As a new method, other studies should be carried out in order to validate its use in monitoring caries lesions.

\subsection{Light-emitting devices}

Other method used for caries detection is based on optical properties from sound and carious dental tissues.

Fluorescence is a phenomenon where the light is absorbed in a specific wavelength and then emitted in a higher wavelength. This characteristic has been observed in the dental tissues, since the pattern of light absorption and reemission (spectrum of fluorescence) of the dental tissues varies according to the excitation light wavelength (Benedict, 1928). Thus, light absorption and reemission is different in the enamel, dentin and cementum, as well as in sound and carious tissues. For this reason, fluorescence can be used for the detection and subsequent diagnosis of dental caries.

The natural fluorescence of hard dental tissues has been studied since long time ago. It is well known that as the enamel as the dentin shows an auto-fluorescence. In this way, caries lesions, dental plaque and microorganisms also show fluorescent components. It has been observed that the difference between natural fluorescence of sound and carious dental tissues can be quantified using light-emitting devices, such as laser, xenon or LED.

\subsubsection{Laser fluorescence devices (DIAGNOdent and DIAGNOdent pen)}

Laser fluorescence device is a non-invasive and quantitative method based on the laserinduced fluorescence. The first laser fluorescence device, DIAGNOdent 2095 (KaVo, Biberach, Germany), was developed in 1998 (Figure 5). It is based on the quantification of emitted fluorescence from organic components of dental tissues when excited by a $655 \mathrm{~nm}$ laser diode (aluminum, gallium, indium and phosphorus - AlGaInP) located on the red range from the visible spectrum.

The emitted light reaches the dental tissues through a flexible tip. As the mature enamel is more transparent, this light passes through this tissue without being deflected. In contact with affected enamel, this light will be diffracted and dispersed. The later is able to excite either the hard dental tissue, resulting in the tissue autofluorescence, or fluorophores present in the caries lesions. These fluorophores derived from the products of the bacterial metabolism and has been identified as porphyrins (Hibst et al., 2001). The emitted fluorescence by the porphyrins is collected by nine concentric fibers and translated into 
numeric values, which can vary from 0 to 99 . Two optical tips are available: tip A for occlusal surfaces, and tip B for smooth surfaces. This device has shown good results in the detection of occlusal caries, however, it might not be used as the only method for treatment decision-making process (Bader \& Shugars, 2006; Rodrigues et al., 2008).

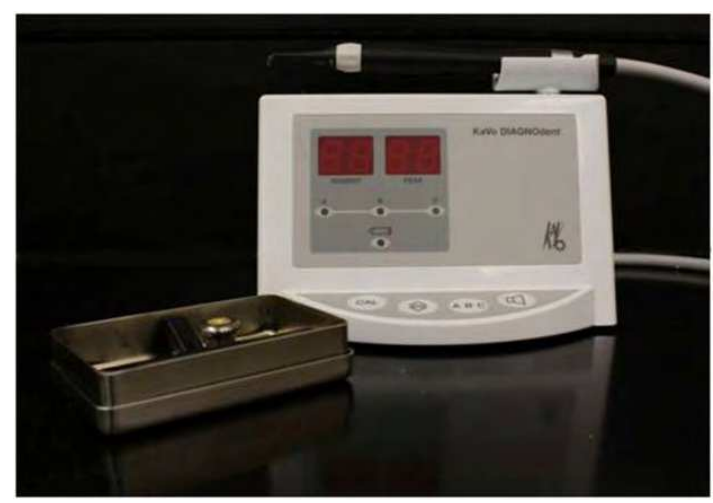

Fig. 5. DIAGNOdent 2095 - a laser fluorescence device for caries detection.

Recently, a new and compact device - DIAGNOdent 2190 or DIAGNOdent pen - (KaVo, Biberach, Germany) (Figure 6) has been introduced in the market. This device functions on the same principle as the earliest. For this reason, the device was condensed and the tips were modified. The tips used in this device are made from sapphire fiber and the same solid single sapphire fiber tip is used for propagation of the excitation and for collection of the fluorescence light, but in opposite directions and different wavelengths (Lussi \& Hellwig, 2006). There are two tips which can be coupled on this device: an occlusal and an approximal tip. However, its performance in approximal surfaces is still limited. The device weights $140 \mathrm{~g}$ and only one battery $(1,5 \mathrm{~V})$ is needed.

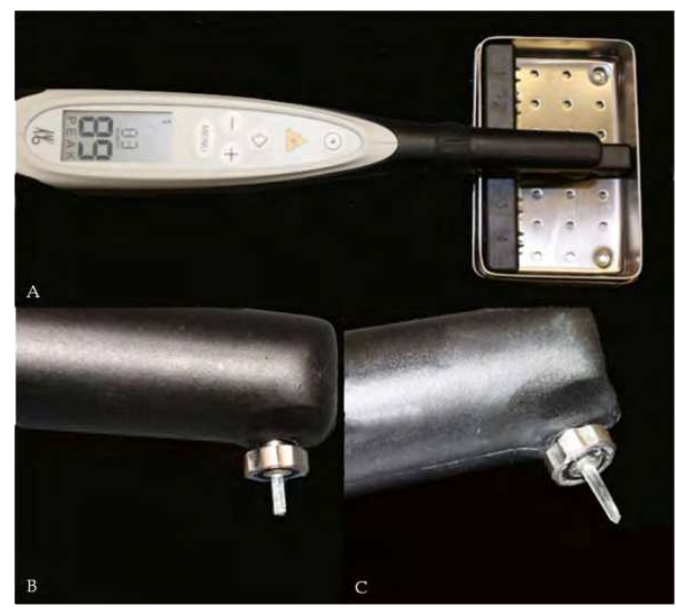

Fig. 6. (A) DIAGNOdent 2190 or DIAGNOdent pen calibration against the standard ceramic. (B) Occlusal tip. (C) Approximal tip. 
As mentioned before, when a caries lesion or a dental surface is assessed by DIAGNOdent, a value between 0 and 99 is observed. This value is, theoretically, related to the lesion depth. For the values interpretation, several cut-off points have been proposed in the literature, as for DIAGNOdent as for DIAGNOdent pen. These cut-off points differ from each other in some units in the enamel and dentin. For this reason, is recommended that the clinician considers the values as an interval for the interpretation and also associates clinical and radiographic characteristics for the correct assessment of the lesions.

Other factor that might be addressed is the presence of stains due to inactive lesions or calculus on the occlusal surfaces due to biological sealing. Both can result in high values of fluorescence and, in consequence, false-positive results. Therefore, as also recommended before visual examination, cleansing of dental surfaces should be performed before laser fluorescence measurements. Besides, after professional prophylaxis using bicarbonate powder or prophylactic paste, it is important that the dental surface is rinsed off, so powder or paste does not remain in the fissure or inside microcavities. This could influence the laser fluorescence measurements (Diniz et al., 2011; Lussi \& Reich, 2005).

In conclusion, the clinician who intends to use this method as a auxiliary in the caries detection process should be aware of the correct device functioning and remember that several factors might interfere the results, such as staining, calculus or powder/paste remnants; calibration procedures; and cut-off points variation for enamel and dentin caries.

For this reason, DIAGNOdent or DIAGNOdent pen should not be used as major method for caries detection, but as a supplementary tool for both visual and radiographic examination. Some situations, in which the professional is in doubt concerning the presence of a caries lesion on a surface free of staining, those devices can be suggested as substitutes for the radiographic examination. Besides, in the pediatric dentistry field, their use can also be suggested when X-ray examination is not possible due to the child behavior or during examination of patients with special needs or disabilities.

\subsubsection{Quantitative light-induced fluorescence (QLF)}

Quantitative light-induced fluorescence (QLF) (QLF-clin, Inspektor Research Systems BV, Amsterdam, Netherlands) (Figure 7) was developed for use in caries detection and it is available commercially for clinical use. This device consists of a handheld intraoral color microvideo CCD camera, interfaced with a personal computer and custom software (QLFpatient, Inspektor Research Systems BV, Amsterdam, Netherlands). The software enables to capture and to analyze in vivo images of the tooth during clinical examination.

QLF uses a 50-watt xenon arc-lamp and an optical filter in order to produce a blue light with a 290- to 450-nm wavelength, which is carried to the tooth through a light guide fitted with a dental mirror. The fluorescence images are filtered by a yellow high-pass filter $(\lambda \geq 540 \mathrm{~nm})$ and then captured by a color CCD camera (Al-Khateeb et al., 1997). When the tooth surface is illuminated by this high-intensity blue light, autofluorescence of the enamel is obtained by the intraoral camera, since all excitation light reflected or diffused is filtered. When a lesion is present on the surface, an increase in light scattering is observed relative to the surrounding enamel. The result of this is that the contrast between sound enamel and a carious lesion is improved with the lesion seen as being dark on a light green background (Neuhaus et al., 2009). 


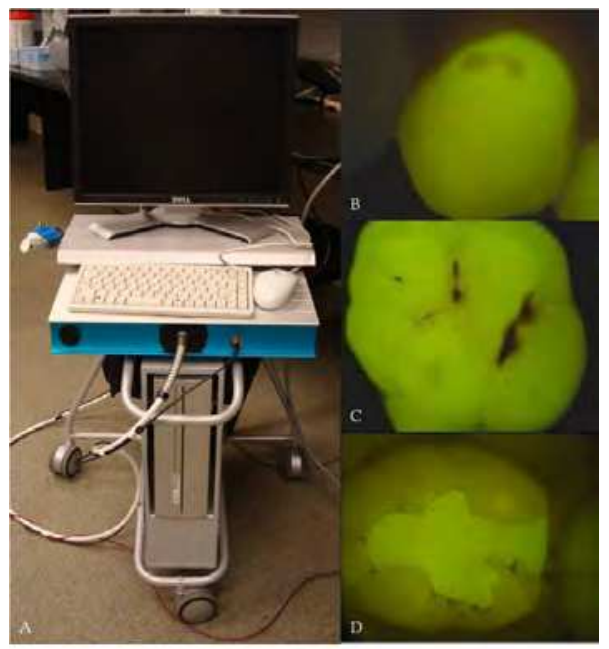

Fig. 7. (A) QLF system. (B) Fluorescence image of an enamel caries lesion on the buccal surface. (C) Fluorescence image of an occlusal caries lesion. (D) Fluorescence image of a secondary caries lesion around a composite restoration

To enable calculation of fluorescence loss in the caries lesion, the fluorescence of healthy tissue that was originally present at the lesion site is rebuilt by extrapolation of the fluorescence of healthy tissue that is found around the caries lesion. The difference between the lesion values and the reconstructed values allows the calculation of fluorescence loss. The fluorescence emitted is directly related to the mineral content of the enamel. Thus, the image can be used later to quantify the size, depth and volume of carious lesion produced by the parameters produced by the software: lesion area (in square millimeters), lesion depth $-\Delta \mathrm{F}$ (percentage of fluorescence loss) and volume of carious lesion - $\Delta \mathrm{Q}$ (the product of the lesion area in $\mathrm{mm}^{2}$ and the lesion depth in percentage of fluorescence loss) (Zandoná \& Zero, 2006).

Through these parameters, it is possible to detect and differentiate caries lesions at an early stage of development, making this system a sensitive method for quantification of enamel caries. Another advantage is that the image can be stored and used to motivate patients to seek healthcare and to prevent dental disease through education during routine preventive care. However, this method is more complicated, since the use of QLF consists of three main steps. The first is lesion detection by the examiner and subsequent capturing of an image of the lesion. Second, quantitative analysis is done of the image. Finally, the third step involves the long-term monitoring of the caries lesions, which enjoys the benefit of an innovative video repositioning part of the software, setting the initial image and the live image based on the geometry of similar fluorescence intensities. For that, it is necessary that the images of the tooth surfaces should be captured in the same position and angulation. Thus, same magnification images obtained at different observation times could be compared (Buchalla et al., 2001).

This fluorescence method has demonstrated that it can be reliably used by different examiners (Eggertsson et al., 1999). The literature demonstrates the diverse QLF 
applicability, such as detecting incipient primary lesions, secondary and root caries on smooth and occlusal surfaces in both primary and permanent teeth; detecting demineralization around orthodontic components; monitoring demineralization and remineralization caries lesion processes; quantifying dental plaque, erosion and fluorosis; monitoring caries removal; and detecting removal of extrinsic stains after tooth whitening (Al-Khateeb et al., 1997 ; Eggertsson et al., 1999; Neuhaus et al., 2009 ; Zandoná \& Zero, 2006). However, it is important to emphasize that QLF can be influenced by some factors, such as stains, dental plaque, dental fluorosis or hypomineralization. Thus, as the presence of these confounding factors can produce images with similar appearance to that of dental demineralization, it is important that dental professionals should recognize those factors and differentiate them to perform a correct diagnosis.

QLF device has demonstrated potential to detect and longitudinally monitor caries lesions. In addition, it can provide dental professionals with significant information related to caries lesions severity. However, it should be emphasized that the information provided by QLF, as in all supplemental methods, can never be used by itself for clinical decision support. This information should be carefully evaluated and integrated to other individual patient factors and professional experience before making a definitive diagnosis and treatment plan.

\subsubsection{Fluorescence camera (VistaProof)}

Another device based on the light-induced fluorescence phenomenon is the intraoral camera VistaProof (Dürr Dental, Bietigheim-Bissingen, Germany) (Figure 8) that is based on six blue GaN-LEDs emitting a 405-nm light. With this camera it is possible to digitize the video signal from the dental surface during fluorescence emission using a CCD sensor (chargecoupled device). On these images, it is possible to see different areas of the dental surface that fluoresce in green (sound dental tissue) and in red (carious dental tissue) (Thoms, 2006). DBSWIN software is used to analyze the images and translate into values the intensity ratio of the red and green fluorescence. According to the manufacturer, those values are related to the lesion extension. The higher is the bacterial colonization, the higher is the red fluorescent signal. The software highlights the lesions and classifies them in a scale from 0 to 5 , giving a treatment orientation in the first evaluation: monitoring, remineralization or invasive treatment. However, these values still need to be adjusted (Rodrigues et al., 2008, 2011). Recently, this device showed a good performance in detecting and quantifying dental plaque formed over smooth surfaces under high exposition to sucrose (Raggio et al., 2010).

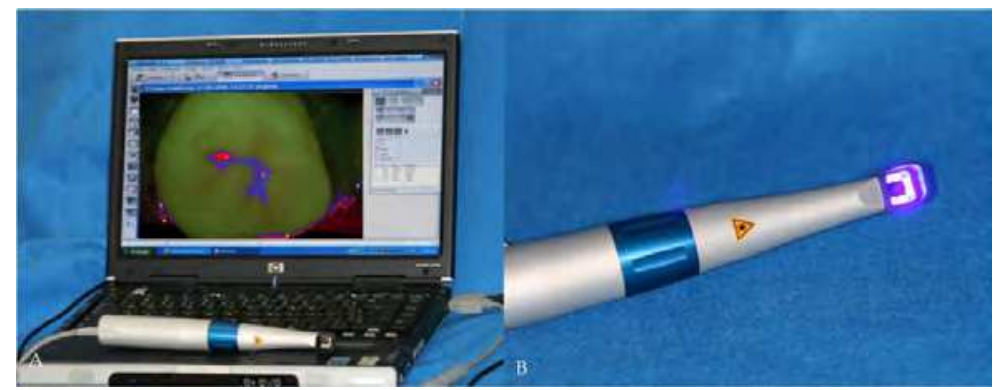

Fig. 8. (A) VistaProof fluorescence camera and DBSWIN software analysis. (B) Six blue LEDs emitting a 405-nm light. 
An advantage of this method is that the patient can see in the computer screen the whole process of caries detection and visualize tooth areas where the disease shows more severe signals. This method makes easier the explanation to the patient concerning his/her clinical situation and possible available treatments. Besides, it is possible to monitor the caries lesion progression or arrestment overtime, as the images of the dental surfaces can be stored in the computer.

\subsubsection{LED technology (Midwest Caries I.D.)}

Recently, another device for caries detection was developed on LED technology - Midwest Caries I.D. - (DENTSPLY Professional, York, PA, USA) (Figure 9). The handheld device emits a soft light emitting diode (LED) between $635 \mathrm{~nm}$ and $880 \mathrm{~nm}$ and analyzes the reflectance and refraction of the emitted light from the tooth surface, which is captured by fiber optics and is converted to electrical signals for analysis. The microprocessor of the device contains a computer-based algorithm that identifies the different optical signature (changes in optical translucency and opacity) between healthy and demineralized tooth (Strassler and Sensi, 2008).

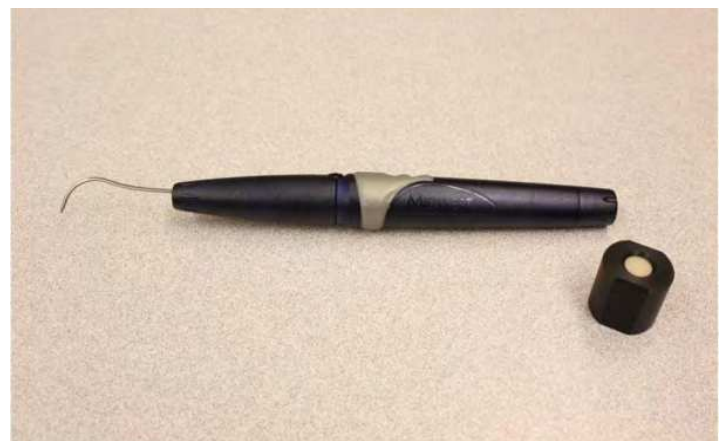

Fig. 9. Midwest Caries I.D. device and the standard for calibration procedure.

The demineralization leads to a change in the LED from green to red with a simultaneous audible signal, which is directly related to the severity of caries lesions. According to the manufacturer, when there is a change in the optical translucency and opacity of the dental tissues, the emitted green light changes to red and an audible signal could be heard. The faster the signal, the deeper the lesion. In the literature, there is only one published study which evaluated the Midwest Caries I.D. in vitro performance for occlusal caries detection (Rodrigues et al., 2011). In this study, the device presented the same cut-off limits for cariesfree sites and enamel caries. This means that the Midwest Caries I.D. was not able to differentiate enamel lesions from sound surfaces.

\subsubsection{Fiber-optic transillumination (FOTI) and digital imaging fiber-optic transillumination (DIFOTI)}

Fiber-optic transillumination (FOTI) and digital imaging fiber-optic transillumination (DIFOTI) have been introduced to improve early detection of carious surfaces and have been accepted by clinicians as a supplementary tool during clinical examinations. 
FOTI (Figure 10) device is a practical, easy, fast and inexpensive method of imaging teeth in the presence of multiple scattering. It is based on the changes in the scattering and absorption phenomenon of light photons that increases the contrast between sound and enamel caries. In other words, results from a local decrease of transillumination owing to the characteristics of the carious lesion. The illumination is delivered via fiber-optics from a light source to a tooth surface. The light propagates from the fiber illuminator across tooth tissue to non-illuminated surfaces. The resulting images of light distribution are then used for diagnosis. Its transmission can be observed either in the opposite side or in the occlusal surfaces, when molars and premolars are analyzed. As light scattering is higher in the demineralized enamel, it is possible to see the lesion as a dark area or a shadow. Besides, carious dentin appears orange, brown or grey underneath the enamel. This can help on the differentiation between enamel and dentin lesions. However, it has been show that FOTI diagnosis by naked eye can be subject to great inter- and intra-examiner variation (Neuhaus et al., 2009).

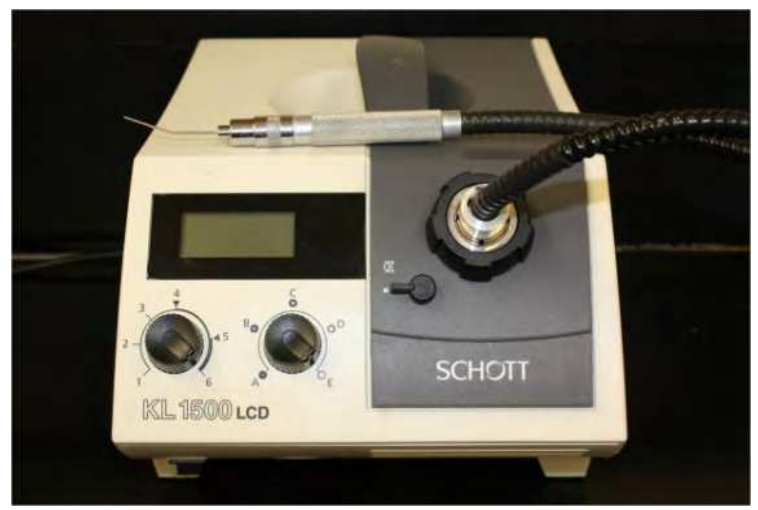

Fig. 10. Fiber-optic transillumination (FOTI).

To overcome the variability dilemma in FOTI, a new method has been tested. DIFOTI (Figure 11) is a method which employs digital image processing for quantitative diagnosis and prognosis in dentistry. It is based on light propagation just below the tooth surface and can be used to determine lesion depth. It uses fiber-optic transillumination of safe visible light to image the tooth. In this system, light delivered by a fiber-optic is collected on the other side of the tooth by a mirror system and recorded with a CCD imaging camera, instantaneously. Thus, DIFOTI images can be acquired in repeatable fashion by maintaining adjustment of a number of imaging control parameters. Then the acquired information is sent to a computer for analysis with dedicated algorithms, which produce digital images that can be viewed by the dentist and patient in real time or stored for later assessment. In addition, this system can use digital image processing methods to enhance contrast between sound and carious tissues and to quantify features of incipient, frank and secondary caries lesions on occlusal, approximal and smooth surfaces. It can also be used to detect other changes in coronal tooth anatomy, such as tooth fractures and fluorosis. DIFOTI presents higher sensitivity in detection early lesions when compared to the radiographic examination and has potential for quantitative monitoring of selected lesions over a period of time (BinShuwaish et al., 2008; Young \& Featherstone, 2005). 


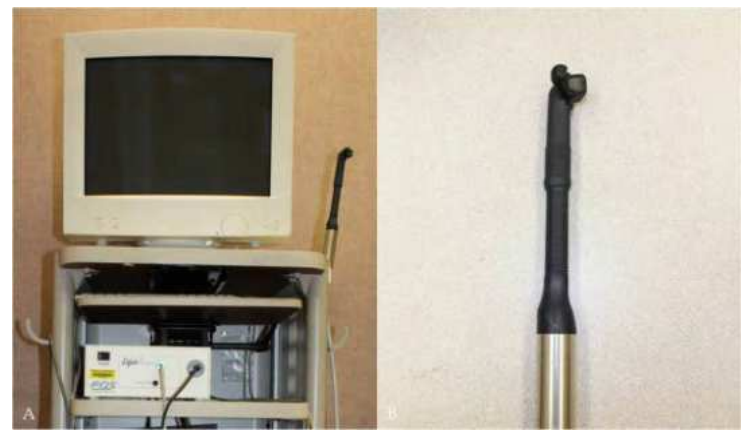

Fig. 11. (A) Digital imaging fiber-optic transillumination (DIFOTI). (B) Tip for occlusal surfaces.

\subsubsection{Electrical caries monitor (ECM)}

Over the last decades, the relationship between the extent of caries in teeth and electrical resistance has been investigated. It is possible to assess caries lesions considering the various parameters affecting the electrical measurements of teeth, such as porosity, surface area of the contact "electrode", the thickness of the enamel and dentin tissues, hydration of the enamel, temperature, ionic content of the dental tissue fluids, and the maturation time of the tooth in the oral environment (Neuhaus et al., 2009).

The studies on electrical caries monitor device (ECM) (Figure 12) have assessed these parameters in a "site-specific" or "surface specific" mode. This method has shown different results of reproducibility and validity (Huysmans et al., 2005; Kühnisch et al., 2006). Some in vitro studies indicated that the presence of stain is a confounder for ECM measurements. Besides, the different cut-off limits for enamel and dentin caries lesions may be needed for stained teeth (Côrtes et al., 2003; Ellwood \& Côrtes, 2004). Therefore, its indication in the clinical practice is still uncertain. Further in vivo studies are necessary in order to make this technology useful in the practice.

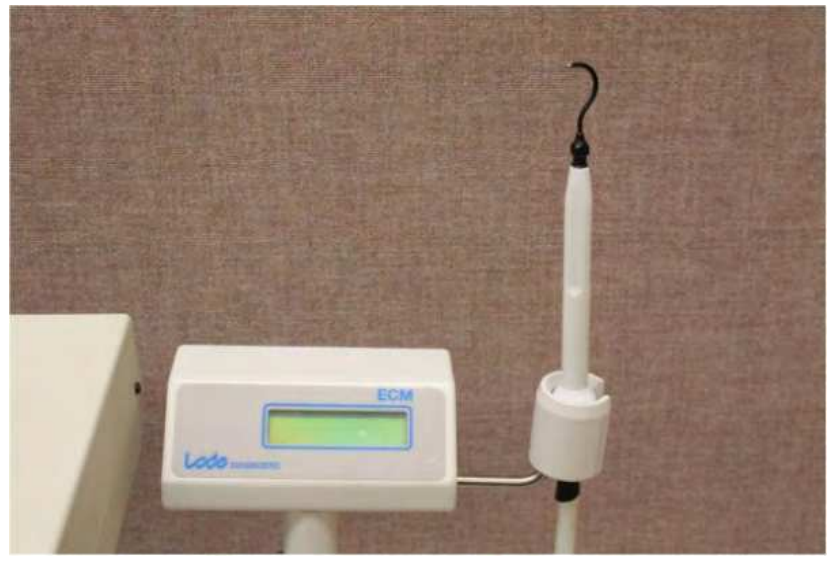

Fig. 12. Electrical caries monitor (ECM). 


\section{Conclusion}

Visual examination, by observing clinical characteristics and appearance of the lesions, associated to radiographs is able to provide most of necessary information to the clinician for the detection of caries lesions. However, only severe and deep lesions are detected by radiographic examination. Therefore, auxiliary methods can contribute positively in the process of detection and their utilization should be encouraged. However, the clinician should be aware of their correct use and follow the manufacturer instructions. Besides, it should be kept in mind their disadvantages and affecting factors. This could provide more information for treatment decision-making process.

Moreover, it is important to state that the detection of caries lesions is only a part of the process of diagnosis. Other factors might be assessed, such as risk and caries activity, oral hygiene habits and fluoride exposition.

\section{References}

Al-Khateeb, S. ; Ten Cate, J.M, ; Angmar-Månsson, B. ; De Josselin de Jong, E. ; Sundström, G.; Exterkate, R.A. \& Oliveby, A. (1997). Quantification of formation and remineralization of artificial enamel lesions with a new portable fluorescence device. Advances in Dental Research, Vol.11, No.4, (November), pp. 502-506, ISSN 0895-9374

Araújo, F.B.; Araújo, D.R.; Santos, C.K. \& Souza, M.A. (1996). Diagnosis of approximal caries in primary teeth: radiographic versus clinical examination using tooth separation. American Jounal of Dentistry, Vol.9, No.2, (April), pp. 54-56, ISSN 0894-8275

Bader, J.D.; Shugars, D.A. \& Bonito, A.J. (2001). Systematic reviews of selected dental caries diagnosis and management methods. Journal of Dental Education, Vol.65, No.10, (October), pp. 960-968, ISSN 0022-0337

Bader, J.D. \& Shugars, D.A. (2006). The evidence supporting alternative management strategies for early occlusal caries and suspected occlusal dentinal caries. Journal of Evidence-Based Dental Practice, Vol.6, No.1, (March), pp. 91-100, ISSN 1532-3382

Benedict, H.C. (1928). A note on the fluorescence of teeth in ultra-violet rays. Science, Vol.67, No.1739, (April), pp. 442, ISSN 0036-8075

Berry, H.M.Jr. (1983). Cervical burnout and Mach band: two shadows of doubt in radiologic interpretation of carious lesions. Journal of the American Dental Association, Vol.106, No.5, (May), pp. 622-625, ISSN 0002-8177

Bin-Shuwaish, M.; Dennison, J.B.; Yaman, P. \& Neiva, G. (2008). Estimation of clinical axial extension of class II caries lesions with ultraspeed and digital radiographs: an invivo study. Operative Dentistry, Vol.33, No.6, (November-December), pp. 613-621, ISSN 0361-7734

Bjørndal, L. \& Thylstrup, A. (1995). A structural analysis of approximal enamel caries lesions and subjacent dentin reactions. European Journal of Oral Sciences, Vol.103, No.1, (February), pp. 25-31, ISSN 1600-0722

Braga, M.M.; Mendes, F.M.; Martignon, S.; Ricketts, D.N. \& Ekstrand, K.R. (2009). In vitro comparison of Nyvad's system and ICDAS-II with Lesion Activity Assessment for evaluation of severity and activity of occlusal caries lesions in primary teeth. Caries Research, Vol.43, No.5, (September), pp. 405-412, ISSN 0008-6568

Braga, M.M.; Ekstrand, K.R.; Martignon, S.; Imparato, J.C.; Ricketts, D.N. \& Mendes, F.M. (2010). Clinical performance of two visual scoring systems in detecting and 
assessing activity status of occlusal caries in primary teeth. Caries Research, Vol.44, No.3, (June), pp. 300-308, ISSN 0008-6568

Buchalla, W., De Josselin de Jong, E.; Ando, M.; Eggertssonn, H.; Lennon, A. \& Stookey, G.K. (2001). Video-repositioning - increased repeatability for QLF caries monitoring method. Journal of Dental Research, Vol.80, No.1 Suppl, (March), pp. 115, ISSN 0022-0345

Côrtes, D.F.; Ellwood, R.P. \& Ekstrand, K.R. (2003). An in vitro comparison of a combined FOTI/visual examination of occlusal caries with other caries diagnostic methods and the effect of stain on their diagnostic performance. Caries Research, Vol.37, No.1, (January-February), pp. 8-16, ISSN 0008-6568

Diniz, M.B., Rodrigues, J.A.; Hug, I.; Cordeiro, R.C. \& Lussi, A. (2009) Reproducibility and accuracy of the ICDAS-II for occlusal caries detection. Community Dentistry and Oral Epidemiology, Vol.37, No.5, (October), pp. 399-404, ISSN 0301-5661

Diniz, M.B.; Rodrigues, J.A.; Neuhaus, K.W.; Cordeiro, R.C. \& Lussi, A. (2010). Influence of examiner's clinical experience on the reproducibility and accuracy of radiographic examination in detecting occlusal caries. Clinical Oral Investigations, Vol.14, No.5, (October), pp. 515-523, ISSN 1432-6981

Diniz, M.B.; Lima, L.M.; Eckert, G.; Zandona, A.G.; Cordeiro, R.C. \& Pinto, L.S. (2011). In vitro evaluation of ICDAS and radiographic examination of occlusal surfaces and their association with treatment decisions. Operative Dentistry, Vol.36, No.2, (March-April), pp. 133-142, ISSN 0361-7734

Diniz, M.B.; Sciasci, P.; Rodrigues, J.A.; Lussi, A. \& Cordeiro, R.C. (2011). Influence of different professional prophylactic methods on fluorescence measurements for detection of occlusal caries. Caries Research, Vol.45, No.3, (May), pp. 264-268, ISSN 0008-6568

Dove, S.B. (2001). Radiographic diagnosis of dental caries. Journal of Dental Education, Vol.65, No.10, (October), pp. 985-990, ISSN 0022-0337

Eggertsson, H. ; Ferreira-Zandoná, A.G. ; Ando, M. ; González-Cabezas, C. ; Fontana, M. ; Martinez-Mier, E.A. ; Waskow-Chin, J.R.; Jackson, R.D.; Eckert, G.J.; Stookey, G.K. \& Zero, D.T. (1999). Reproducibility of in vitro and clinical examinations with QLF (Quantitative Light-Induced Fluorescence). Developing guidelines for imaging and analyzing QLF images, and a process for training examiners. In: Early detection of dental caries III: Proceedings of the $6^{\text {th }}$ Annual Indiana Conference, Stookey, G.K., pp. 213-228, Indiana University School of Dentistry, ISBN 0-9655 149-2-7, Indianapolis.

Ekstrand, K.; Qvist, V. \& Thylstrup, A. (1987). Light microscope study of the effect of probing in occlusal surfaces. Caries Research, Vol.21, No.4, pp. 368-374, ISSN 0008-6568

Ekstrand, K.R. \& Bjørndal, L. (1997). Structural analysis of plaque and caries in relation to the morphology of the groove-fossa system on erupting mandibular third molars. Caries Research, Vol.31, No.5, pp. 336-348, ISSN 0008-6568

Ekstrand, K.R.; Ricketts, D.N. \& Kidd, E.A. (1997). Reproducibility and accuracy of three methods for assessment of demineralization depth on the occlusal surface: an in vitro examination. Caries Research, Vol.31, No.3, pp. 224-231, ISSN 0008-6568

Ekstrand, K.R.; Martignon, S.; Ricketts, D.J. \& Qvist, V. (2007). Detection and activity assessment of primary coronal caries lesions: a methodologic study. Operative Dentistry, Vol.32, No.3, (May-June), pp. 225-235, ISSN 0361-7734

Ekstrand, K.R.; Zero, D.T.; Martignon, S. \& Pitts, N.B. (2009). Lesion activity assessment. Monographs of Oral Science, Vol.21, (June), pp. 63-90, ISSN 0077-0892

Ellwood, R. \&, Côrtes, D.F. (2004). In vitro assessment of methods of applying the electrical caries monitor for the detection of occlusal caries. Caries Research, Vol.38, No.1, (January-February), pp. 45-53, ISSN 0002-8177 
Espelid, I.; Tveit, A.B. \& Fjelltveit, A. (1994). Variations among dentists in radiographic detection of occlusal caries. Caries Research, Vol.28, No.3, pp. 169-175, ISSN 0008-6568

Hamilton, J.C. (2005). Should a dental explorer be used to probe suspected carious lesions? Yes - an explorer is a time-tested tool for caries detection. Journal of the American Dental Association, Vol.136, No.11, (November), pp. 1526, 1528, 1530, passim, ISSN 0002-8177

Hekmatian, E.; Sharif, S. \& Khodaian, N. (2005). Literature review: digital subtraction radiography in dentistry. Dental Research Journal, Vol.2, No.2, pp. 1-8, ISSN 1735-3327

Hibst, R.; Paulus, R. \& Lussi, A. (2001). A detection of occlusal caries by laser fluorescence: basic and clinical investigations. Medical Laser Application, Vol.16, No.3, (June), pp. 295-13, ISSN 1615-1615

Hintze, H.; Wenzel, A.; Danielsen, B. \& Nyvad, B. (1998). Reliability of visual examination, fibre-optic transillumination, and bite-wing radiography, and reproducibility of direct visual examination following tooth separation for the identification of cavitated carious lesions in contacting approximal surfaces. Caries Research, Vol.32, No.3, pp. 204-209, ISSN 0002-8177

Huysmans, M.C.; Kühnisch, J. \& ten Bosch, J.J. (2005). Reproducibility of electrical caries measurements: a technical problem? Caries Research, Vol.9, No.5, (SeptemberOctober), pp. 403-410, ISSN 0002-8177

Ismail, A.I.; Sohn, W.; Tellez, M.; Amaya, A.; Sen, A.; Hasson, H. \& Pitts, N.B. (2007). The International Caries Detection and Assessment System (ICDAS): an integrated system for measuring dental caries. Community Dentistry and Oral Epidemiology, Vol.35, No.3, (June), pp. 170-178, ISSN 0301-5661

Jablonski-Momeni, A.; Stachniss, V.; Ricketts, D.N.; Heinzel-Gutenbrunner, M. \& Pieper, K. (2008). Reproducibility and accuracy of the ICDAS-II for detection of occlusal caries in vitro. Caries Research, Vol.42, No.2, (January), pp. 79-87, ISSN 0002-8177

Kidd, E.A. \& Fejerskov, O. (2004). What constitutes dental caries ? Histophatology of carious enamel and dentin related to the action of cariogenic biofilms. Journal of Dental Research, Vol.83, No. Spec No C, pp. C35-C38, ISSN 0022-0345

Kühnisch, J.; Heinrich-Weltzien, R.; Tabatabaie, M.; Stösser, L. \& Huysmans, M.C. (2006). An in vitro comparison between two methods of electrical resistance measurement for occlusal caries detection. Caries Research, Vol.40, No.2, pp. 104-111, ISSN 0002-8177

Lagerlöf, F. \& Oliveby, A. (1996). Clinical implications: new strategies for caries treatment. In: Early detection of dental caries: Proceedings of the 1st Annual Indiana Conference, Stookey, G.K., pp. 297-321, Indiana University School of Dentistry, ISBN 0-9655 149-2-7, Indianapolis.

Loesche, W.J.; Svanberg, M.L. \& Pape, H.R. (1979). Intra oral transmission of Streptococcus mutans by a dental explorer. Journal of Dental Research, Vol.58, No.8, (August), pp. 1765-1770, ISSN 0022-0345

Longbottom, C.; Ekstrand, K. \& Zero, D. (2009). Traditional preventive treatment options. Monographs in Oral Science, Vol.21, (June), pp. 149-155, ISSN: 0077-0892

Lussi, A. (1993). Comparison of different methods for the diagnosis of fissure caries without cavitation. Caries Research, Vol.27, No.5, pp. 409-416, ISSN 0002-8177

Lussi, A. \& Reich, E. (2005). The influence of toothpastes and prophylaxis pastes on fluorescence measurements for caries detection in vitro. European Journal of Oral Sciences, Vol.113, No.2, (April), pp. 141-144, ISSN 1600-0722

Lussi, A.; Hack, A.; Hug, I.; Heckenberger, H.; Megert, B. \& Stich, H. (2006). Detection of approximal caries with a new laser fluorescence device. Caries Research, Vol.40, No.2, pp. 97-103, ISSN 0002-8177 
Lussi, A. \& Hellwig, E. (2006). Performance of a new laser fluorescence device for the detection of occlusal caries in vitro. Journal of Dentistry, Vol.34, No.7, (January), pp. 467-471, ISSN 0300-5712

Mejàre, I. \& Kidd, E.A.M. (2008). Radiography for caries diagnosis. In: Dental caries: the disease and its clinical management, Fejerskov, O. \& Kidd, E.A.M., pp. 69-89, Blackwell Munksgaard, ISBN 9781405138895, Oxford.

Mortimer, K.V. (1970). The relationship of deciduous enamel structure to dental disease. Caries Research, Vol.4, No.3, pp. 206-223, ISSN 0002-8177

Neuhaus, K.W.; Longbottom, C.; Ellwood, R. \& Lussi, A. (2009). Novel lesion detection aids. Monographs in Oral Science, Vol.21, (June), pp. 52-62, ISSN: 0077-0892

Neuhaus, K.W.; Rodrigues, J.A.; Hug, I.; Stich, H. \& Lussi, A. (2010). Performance of laser fluorescence devices, visual and radiographic examination for the detection of occlusal caries in primary molars. Clinical Oral Investigations, May 27 (Epub ahead of print).

Nyvad, B.; Machiulskiene, V. \& Baelum, V. (1999). Reliability of a new caries diagnostic system differentiating between active and inactive caries lesions. Caries Research, Vol.33, No.4, (July-August), pp. 252-260, ISSN 0002-8177

Nyvad, B.; Machiulskiene, V. \& Baelum, V. (2003). Construct and predictive validity of clinical caries diagnostic criteria assessing lesion activity. Journal of Dental Research, Vol.82, No.2, (February), pp. 117-22, ISSN 0022-0345

Nyvad, B. (2004). Diagnosis versus detection of caries. Caries Research, Vol.38, No.3, (MayJune), pp. 192-198, ISSN 0002-8177

Nyvad, B.; Fejerskov, O. \& Baelum, V. (2008). Visual-tactile caries diagnosis. In: Dental caries: the disease and its clinical management, Fejerskov, O. \& Kidd, E.A.M., pp. 49-69, Blackwell Munksgaard, ISBN 9781405138895, Oxford.

Pitts, N.B. \& Rimmer, P.A. (1992). An in vivo comparison of radiographic and directly assessed clinical caries status of posterior approximal surfaces in primary and permanent teeth. Caries Research, Vol.26, No.2, pp. 146-152, ISSN 0002-8177

Pitts, N. (2004). "ICDAS" -- an international system for caries detection and assessment being developed to facilitate caries epidemiology, research and appropriated clinical management. Community Dental Health, Vol.21, No.3, (September), pp. 193198, ISSN 0256-539X

Pitts, N.B. (2004). Modern concepts of caries measurement. Journal of Dental Research, Vol.83, No. Spec No C, p. C43-C47, ISSN 0022-0345

Pitts, N.B. \& Stamm, J.W. (2004). International Consensus Workshop on Caries Clinical Trials (ICW-CCT) -- final consensus statements: agreeing where the evidence leads. Journal of Dental Research, Vol.83, No. Spec No C, pp. C125-C128, ISSN 0022-0345

Pitts, N.B. \& Richards, D. (2009). Personalized treatment planning. Monographs in Oral Science, Vol.21, (June), pp. 128-143, ISSN: 0077-0892

Raggio, D.P.; Braga, M.M.; Rodrigues, J.A.; Freitas, P.M.; Imparato, J.C. \& Mendes, F.M. (2010). Reliability and discriminatory power of methods for dental plaque quantification. Journal of Applied Oral Science, Vol.18, No.2, (March-April), pp. 186193, ISSN 1678-7757

Ratledge, D.K.; Kidd, E.A. \& Beighton, D. (2001). A clinical and microbiological study of approximal carious lesions. Part 1: the relationship between cavitation, radiographic lesion depth, the site specific gingival index and the level of infection of the dentine. Caries Research, Vol.35, No.1, (January-February), pp. 3-7, ISSN 0002-8177

Ricketts, D.N.; Kidd, E.A.; Smith, B.G. \& Wilson, R.F. (1995). Clinical and radio graphic diagnosis of occlusal caries: a study in vitro. Journal of Oral Rehabilitation, Vol.22, No.1, (January), pp. 15-20, ISSN 0305-182X 
Ricketts, D.; Kidd, E.; Weerheijm, K. \& de Soet, H. (1997). Hidden caries: what is it? Does it exist? Does it matter? International Dental Journal, Vol.47, No.5, (October), pp. 25965, ISSN 1875-595X

Ricketts, D.N.; Ekstrand, K.R.; Martignon, S.; Ellwood, R.; Alatsaris, M. \& Nugent, Z. (2007). Accuracy and reproducibility of conventional radiographic assessment and subtraction radiography in detecting demineralization in occlusal surfaces. Caries Research, Vol.41, No.2, pp. 121-128, ISSN 0002-8177

Rodrigues, J.A.; Hug, I.; Diniz, M.B. \& Lussi, A. (2008). Performance of fluorescence methods, radiographic examination and ICDAS II on occlusal surfaces in vitro. Caries Research, Vol.42, No.4, (July), pp. 297-304, ISSN 0002-8177

Rodrigues, J.A.; Hug, I.; Neuhaus, K.W. \& Lussi, A. (2011). Light-emitting diode and laser fluorescence-based devices in detecting occlusal caries. Journal of Biomedical Optics, Vol.16, No.10, pp. 107003-1-107003-5, ISSN 1083-3668

Sanden, E.; Koob, A.; Hassfeld, S. Staehle, H.J. \& Eickholz, P. (2003). Reliability of digital radiography of interproximal dental caries. American Journal of Dentistry, Vol.16, No.3, (June), pp. 170-176, ISSN 0894-8275

Shoiab. L.; Deery, C.; Ricketts, D.N. \& Nugent, Z.J. (2009). Validity and reproducibility of ICDAS II in primary teeth. Caries Research, Vol.43, No.6, (November), pp. 442-448, ISSN 0002-8177

Stookey, G. Should a dental explorer be used to probe suspected carious lesions? No - use of an explorer can lead to misdiagnosis and disrupt remineralization. Journal of the American Dental Association, Vol.136, No.11, (November), pp. 1527, 1529, 1531, ISSN 0002-8177

Strassler, H.E. \& Sensi, L.G. (2008). Technology-enhanced caries detection and diagnosis. Compendium of Continuing Education in Dentistry, Vol.29, No.8, (October), pp. 464$465,468,470$ passim, ISSN 1548-8578

Thoms, M. (2006). Detection of intraoral lesions using a fluorescence camera. Proceedings of SPIE Lasers in Dentistry XII, Vol.6137, No.5, pp. 1-7, ISSN 0002-8177

van der Stelt, P.F. (2008). Better imaging: the advantages of digital radiography. Journal of the American Dental Association, Vol.139, No. Suppl, (June), pp. 7S-13S, ISSN 0002-8177

Varma, S.; Banerjee, A. \& Bartlett, D. (2008). An in vivo investigation of associations between saliva properties, caries prevalence and potential lesion activity in an adult UK population. Journal of Dentistry, Vol.36, No.4, (April), pp. 294-299, ISSN 0300-5712

Wenzel, A. (1995). Current trends in radiographic caries imaging. Oral Surgery, Oral Medicine, Oral Pathology, Oral Radiology, and Endodontics, Vol.80, No.5, (November), pp. 527-539, ISSN 1079-2104

Wenzel, A. (1998). Digital radiography and caries diagnosis. Dentomaxillofacial Radiology, Vol.27, No.1, (January), pp. 3-11, ISSN 0007-1285

Wenzel, A. (2004). Bitewing and digital bitewing radiography for detection of caries lesions. Journal of Dental Research, Vol.83, No. Spec No C, pp. C72-C75, ISSN 0022-0345

Wyne, A.H. \& Guile, E.E. (1993). Caries activity indicators. A review. Indian Journal of Dental Research, Vol.4, No.2, (April-June), pp. 39-46, ISSN 0970-9290

Young, D.A. \& Featherstone, J.D. (2005). Digital imaging fiber-optic trans-illumination, Fspeed radiographic film and depth of approximal lesions. Journal of the American Dental Association, Vol.136, No.12(December), pp. 1682-1687, ISSN 0002-8177

Zandoná, A.F. \& Zero, D.T. (2006). Diagnostic tools for early caries detection. Journal of the American Dental Association, Vol.137, No.12, (December), pp. 1675-1684; quiz 1730, ISSN 0002-8177 


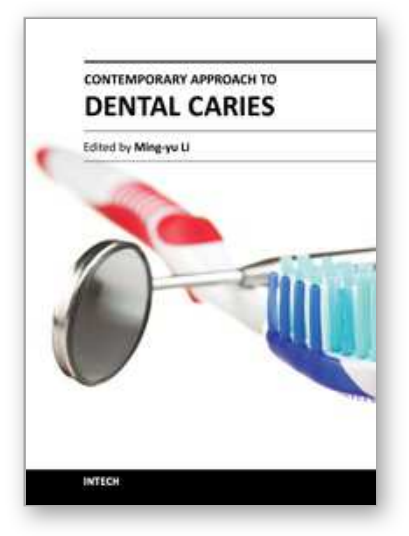

\author{
Contemporary Approach to Dental Caries \\ Edited by Dr. Ming-Yu Li
}

ISBN 978-953-51-0305-9

Hard cover, 488 pages

Publisher InTech

Published online 14, March, 2012

Published in print edition March, 2012

With an update of the recent progress in etiology, pathogenesis, diagnosis, and treatment of caries, it may be said that the final defeat of dental caries is becoming possible soon. Based on the research in this area in recent decades, "Contemporary Approach to Dental Caries" contained the caries in general, the diagnosis of caries, caries control and prevention, the medical treatment of caries, dental caries in children and others such as secondary caries. This book provides the reader with a guide of progress on the study of dental caries. The book will appeal to dental students, educators, hygienists, therapists and dentists who wish to update their knowledge. It will make you feel reading is profitable and useful for your practice.

\title{
How to reference
}

In order to correctly reference this scholarly work, feel free to copy and paste the following:

Michele Baffi Diniz, Jonas de Almeida Rodrigues and Adrian Lussi (2012). Traditional and Novel Caries Detection Methods, Contemporary Approach to Dental Caries, Dr. Ming-Yu Li (Ed.), ISBN: 978-953-51-0305-9, InTech, Available from: http://www.intechopen.com/books/contemporary-approach-to-dental-caries/traditionaland-novel-caries-detection-methods

\section{INTECH}

open science | open minds

\section{InTech Europe}

University Campus STeP Ri

Slavka Krautzeka 83/A

51000 Rijeka, Croatia

Phone: +385 (51) 770447

Fax: +385 (51) 686166

www.intechopen.com

\section{InTech China}

Unit 405, Office Block, Hotel Equatorial Shanghai

No.65, Yan An Road (West), Shanghai, 200040, China

中国上海市延安西路65号上海国际贵都大饭店办公楼405单元

Phone: +86-21-62489820

Fax: +86-21-62489821 
(C) 2012 The Author(s). Licensee IntechOpen. This is an open access article distributed under the terms of the Creative Commons Attribution 3.0 License, which permits unrestricted use, distribution, and reproduction in any medium, provided the original work is properly cited. 